\title{
GENOTOXICITY OF BENZALDEHYDE IN Drosophila melanogaster USING THE WING SOMATIC MUTATION AND RECOMBINATION TEST (SMART) AND PROTEIN PROFILING
}

\author{
*DEEPA P.V., PRIYANKA V., SWARNA R. AND AKSHAYA S.
}

Department of Human Genetics, Sri Ramachandra University, Porur, Chennai-600 116, TN, India.

*Corresponding Author: Email- deepa_305@yahoo.com

Received: June 16, 2012; Accepted: July 10, 2012

\begin{abstract}
Benzaldehyde $\left(\mathrm{C}_{6} \mathrm{H}_{5} \mathrm{CHO}\right)$ is an organic compound which finds a range of applications in many industries. Benzyl derivatives are food additives, used for increasing the taste of food and beverages. It is therefore important to evaluate its genotoxicity and assign the threshold concentration that is permissible for inclusion in edible items. The present study investigated the genotoxic effect of benzaldehyde on Drosophila melanogaster. Two day-old adult males and $3^{\text {rd }}$ instar larvae of Drosophila melanogaster were exposed to varying concentrations of the chemical by allowing them to feed on media, containing benzaldehyde. The treated series were compared to the control group (media mixed with distilled water). Our results demonstrated that benzaldehyde induced genotoxic and mutagenic effects. Benzaldehyde caused increased incidence of mutated phenotypes including orange discoloration of thorax and abdomen that was carried over to the F1 generation. The flies lost their viability at higher concentrations of the drug. To assess the phenotypic mutations at the molecular level, protein profiles of the extracts obtained from $3^{\text {rd }}$ instar larvae from control and drug exposed were compared by SDS PAGE. The protein profiling results demonstrated changes in several major proteins. The Wing Somatic Mutation and Recombination Test (SMART) was used to assess the degree of genotoxicity, by evaluating mitotic recombination and mutations. Trans-heterozygous larvae obtained from the crossing of multiple wing hair and flare $(m w h / f l r 3)$ were subjected to various concentrations of benzaldehyde. Wing analysis showed single spots that represent mutated flr3 clone and twin spots for mutated mwh clone.
\end{abstract}

Key words- Genotoxicity, benzaldehyde, wing spot test/SMART, mutagenicity, SDS PAGE, in-vivo, Drosophila melanogaster.

Citation: Deepa P.V., et al. (2012) Genotoxicity of Benzaldehyde in Drosophila melanogaster using the Wing Somatic Mutation and Recombination Test (SMART) and Protein Profiling. International Journal of Medical and Clinical Research, ISSN:0976-5530 \& E-ISSN:0976-5549, Volume 3, Issue 6, pp.-195-198.

Copyright: Copyright@2012 Deepa P.V., et al. This is an open-access article distributed under the terms of the Creative Commons Attribution License, which permits unrestricted use, distribution and reproduction in any medium, provided the original author and source are credited.

\section{Introduction}

The extensive knowledge of the genetics of $D$. melanogaster and the long term experimental experience with this organism together with extensive genetic homology to mammals has made it uniquely useful in mutation research and genetic toxicology. Many Drosophila genes are homologous to human genes and are studied to gain a better understanding of what role these proteins have in human beings. Apart from being one of the genetically best characterized multicellular eukaryotes, many hundreds of thousands of offspring can be generated in a relatively short period of time (2 weeks at $25^{\circ} \mathrm{C}$ ), easy to maintain and the complete spectrum of somatic and heritable alterations can be detected under the microscope with low power magnification. The examination of the mutants can be done in large numbers and significant data can be collected to demonstrate consistence [1].

Genotoxicity describes a deleterious action on a cell's genetic material affecting its integrity. Genotoxic substances are known to be potentially mutagenic or carcinogenic, specifically those capable of causing genetic mutation and of contributing to the development of tumors. These genotoxic substances include a variety of 
chemical compounds [2]. In the living cell, DNA undergoes frequent chemical change, especially when it is replicated. Most of these changes are quickly repaired. Those that are not, result in a mutation. Thus, mutation is a failure of DNA repair. Mutagens are chemicals or physical factors (such as radiation) that increase the rate of mutation in the cells of bacteria, plants and animals (including humans) [3].

Chemicals able to induce genotoxic effects by mechanisms other than covalent binding are of special interest to scientist [2]. A great deal of work is being devoted to the validation of genotoxicity test procedures able to detect drugs that cause genetic damage by interaction with other cellular targets such as enzymes and microtubules particularly because they play a critical role in DNA replication or in the segregation of chromosomes during cell division [4]. Chemical mutagens are classified as alkylating agents, cross-linking agents and polycyclic aromatic hydrocarbons (PAHs). Alkylating agents act by adding molecular components to DNA bases, which alters the protein product. Cross-linking agents create covalent bonds with DNA bases, while PAHs are metabolized by the human body into other potentially mutagenic molecules.

Benzaldehyde $\left(\mathrm{C}_{6} \mathrm{H}_{5} \mathrm{CHO}\right)$ is an organic compound consisting of a benzene ring with a formyl substituent. It is the simplest aromatic aldehyde and one of the most industrially useful. This colorless liquid has a characteristic pleasant almond-like odor. On oxidation, benzaldehyde is converted into the odorless benzoic acid, which is a common impurity in laboratory samples. Benzyl alcohol can be formed from benzaldehyde by means of hydrogenation. Reaction of benzaldehyde with anhydrous sodium acetate and acetic anhydride yields cinnamic acid, while alcoholic potassium cyanide can be used to catalyze the condensation of benzaldehyde to benzoin. Benzaldehyde undergoes disproportionation upon treatment with concentrated alkali (Cannizzaro reaction): one molecule of the aldehyde is reduced to the corresponding alcohol and another molecule is simultaneously oxidized to sodium benzoate [3].

The food and beverage industry commonly use benzyl derivatives to improve the taste of food and beverages. Research studies conducted "hitherto" have evaluated the genotoxic potential of benzyl derivatives like benzaldehyde, benzyl acetate, benzyl alcohol and benzoic acid in Drosophila using the wing spot assay. Their results have demonstrated the genotoxic effect of the above mentioned benzyl derivatives at higher concentrations [5].

Drug toxicity testing in Drosophila is performed by mixing the food with appropriate concentrations of the drug of choice and exposing the flies to the same for defined time periods. The exposed population and the F1 progeny are microscopically analyzed to look for distinct phenotypic changes.

The gold standard for mutagenicity in Drosophila is the Wing Somatic Mutation and Recombination Test (SMART).It is also referred to as the Wing Spot Assay. Gene mutations, chromosomal rearrangements, chromosome breakage or chromosome loss results in loss of heterozygosity (LOH). Many chemicals are capable of inducing $\mathrm{LOH}$ and SMART is a rapid tool used to assess the ability of a chemical to induce LOH. SMART employs the use of wing cell recessive markers multiple wing hairs (mwh) and flare (flr 3 ) in transheterozygous $m w h+/+f / r 3$ flies. Any genetic change induced in a mitotically dividing cell of a developing wing disc gives rise to a clone(s) of mwh and/or flr3 cells. This results in a visible "spot" on the surface of the wings. Both qualitative and quantitative data about the genetic mutation can be inferred from SMART. The type of clone reveals the different mutational mechanisms involved in clone production whereas the total number of clones induced in the test group of chemically treated flies reveals quantitative data regarding the genotoxicity of the chemical. Also, frequencies of spontaneous LOH in mutants defective in meiotic recombination and disjunction, DNA repair and cell proliferation have been measured using modified SMART system. Point mutation (in flrt or $m w h+$ ), chromosomal alteration(e.g. deletion of flrt or $m w h+)$ or mitotic recombination are indicated by single flr3 or mwh spots (both large and small clones). Whereas twin spots (i.e. patches of adjacent flr3 and mwh cells) are exclusively obtained due to mitotic recombination. Twin spots therefore are indicative of the effects of a compound on recombination $[4,6]$.

\section{Materials and Methods}

Flies were bred in the ratio of 1:3 (males: females) and the cultures were cultured in corn meal agar and maintained at 25 [C during the day and $19 \mathrm{dC}$ in the incubator during night $[7,8]$.

Working concentrations of benzaldehyde of $0.1 \mathrm{mM}, 0.05 \mathrm{mM}$, $0.1 \mathrm{M}, 0.2 \mathrm{M}, 0.3 \mathrm{M}$ and $0.5 \mathrm{M}[6]$ were prepared from the stock solution (1 mg/ml). Instant food (4-24 formula plain - Carolina Biologicals) was mixed with the above test concentrations of benzaldehyde and the food was allowed to set for 3 hours. 30 males were isolated and added to the above and exposed for 24 and 48 hours at $25 \square \mathrm{C}$. After 48 hours, the surviving male flies were transferred (by etherization) to fresh corn meal medium and 90 virgin female flies were added to each of the vials to check the breeding efficiency. All the vials were maintained in duplicates. The control used had instant food mixed with sterile distilled water.

Protein extraction from exposed and unexposed larvae $(0.1 \mathrm{mM}$ and $0.05 \mathrm{mM}$ ) was performed using ReadyPrep Reagent 3 (Bio Rad). Estimation of the isolated protein was performed using Bradford method (595 nm). Protein profiling of Drosophila larvae was performed by sodium dodecyl sulphate polyacrylamide Gel Electrophoresis (SDS-PAGE) using separating gel (acrylamide: bisacrylamide mix - 10\%) and stacking gel (acrylamide: bisacrylamide mix - 4\%).

The Wing Spot Test (SMART) was performed by exposing mwh/ flr3 larvae to the test concentrations of benzaldehyde. The larvae were monitored constantly till emergence and the emerged flies were dissected for their wings and analysis was performed on the wings for spots [9].

\section{Results \\ Phenotypic Changes}

Adult male flies exposed to test concentrations of benzaldehyde survived for 24 and 48 hours. To check their breeding efficiency 90 female flies were added to each vial. The flies bred well. The females laid their eggs in the untreated medium. First instar larvae was observed in 5 days, $2^{\text {nd }}$ instar larvae was observed in 9 days, $3^{\text {rd }}$ instar larvae in about 13 days followed by pupation on the $15^{\text {th }}$ day. Adult flies started emerging from the $19^{\text {th }}$ day. The progeny were screened for pupal lethality, adult emergence and adult mutant phenotypes. The F1 observed under the microscope showed changes in color of the head, thorax and abdomen (Fig. 1). Sur- 
vival rates (exposed and $\mathrm{F} 1$ ) was $100 \%$ in all concentrations except $0.5 \mathrm{M}$, which showed $95 \%$ survival and all the exposed flies demonstrated standard breeding efficiency in all concentrations. Results of exposure to $0.05 \mathrm{mM}, 0.1 \mathrm{mM}, 0.1 \mathrm{M}, 0.2 \mathrm{M}, 0.3 \mathrm{M}$ and $0.5 \mathrm{M}$ concentrations of benzaldehyde are shown in Table 1.

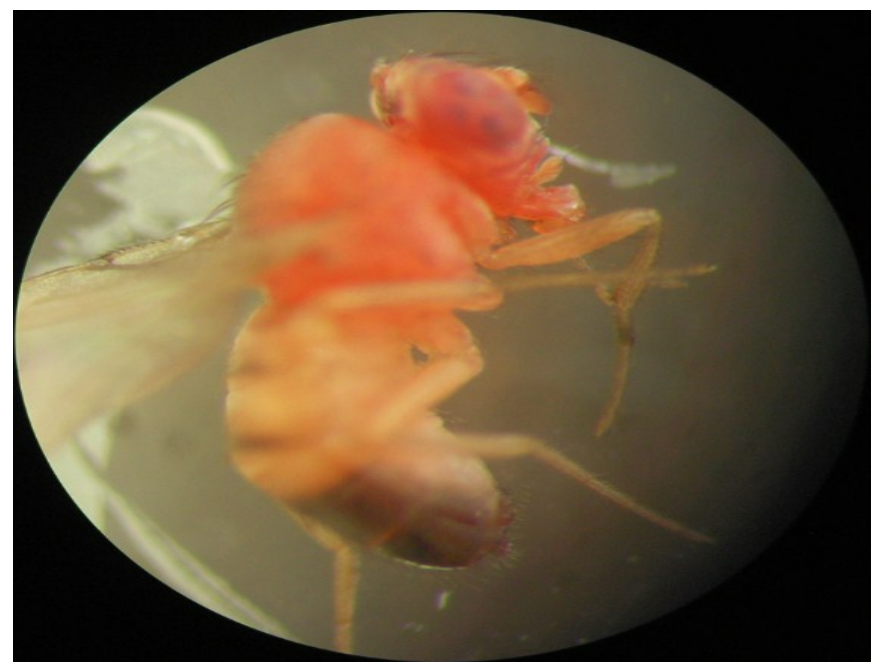

Fig. 1- Phenotypic changes following exposure to benzaldehyde. Note orange discoloration.

This is a photograph of fly exposed to $0.5 \mathrm{M}$ of benzaldehyde. However flies exposed to other ( $0.2 \mathrm{M}$ and $0.3 \mathrm{M})$ concentrations showed similar discoloration.

Table 1- Results (Phenotypic changes) of benzaldehyde exposed flies and their progeny.

\begin{tabular}{|c|c|c|c|}
\hline Experiment & $\begin{array}{l}\text { Concentration of } \\
\text { benzaldehyde }\end{array}$ & $\begin{array}{l}\text { Rate of } \\
\text { Survival }\end{array}$ & Changes Observed \\
\hline 1 & $0.05 \mathrm{mM}$ & $100 \%$ & No significant change. \\
\hline 2 & $0.1 \mathrm{mM}$ & $100 \%$ & No significant change \\
\hline 3 & $0.1 \mathrm{M}$ & $100 \%$ & No significant change. \\
\hline 4 & $0.2 \mathrm{M}$ & $100 \%$ & $\begin{array}{l}\text { Orange discoloration of thorax and } \\
\text { abdomen }\end{array}$ \\
\hline 5 & $0.3 \mathrm{M}$ & $100 \%$ & $\begin{array}{l}\text { Orange discoloration of thorax and } \\
\text { abdomen }\end{array}$ \\
\hline 6 & $0.5 \mathrm{M}$ & $95 \%$ & $\begin{array}{l}\text { Orange discoloration of thorax and } \\
\text { abdomen was much intense. Eye color } \\
\text { was darker }\end{array}$ \\
\hline $\mathrm{F} 1$ analysis & All concentrations & $100 \%$ & $\begin{array}{l}\text { Deep orange discoloration of thorax } \\
\text { and abdomen }\end{array}$ \\
\hline
\end{tabular}

\section{Analysis of Protein Profiles of Drosophila Larvae by SDS - PAGE}

Concentration of proteins in the normal larvae and larvae exposed to varying drugs and concentrations were estimated by Bradford method (absorbance read at $595 \mathrm{~nm}$ ). A standard graph was plot with the given range of protein standards. The concentrations of proteins in the larvae were estimated from the standard graph. The protein yield in $0.1 \mathrm{M}, 0.2 \mathrm{M}, 0.3 \mathrm{M}$ and $0.5 \mathrm{M}$ was very low and not sufficient to perform SDS protein profiling. Hence proteins isolated from $0.05 \mathrm{mM}$ and $0.1 \mathrm{mM}$ was subjected to SDS protein profiling. Comparison of protein profiles between extracts of normal larval extract and larvae exposed to benzaldehyde was done by SDS PAGE (Fig. 2).

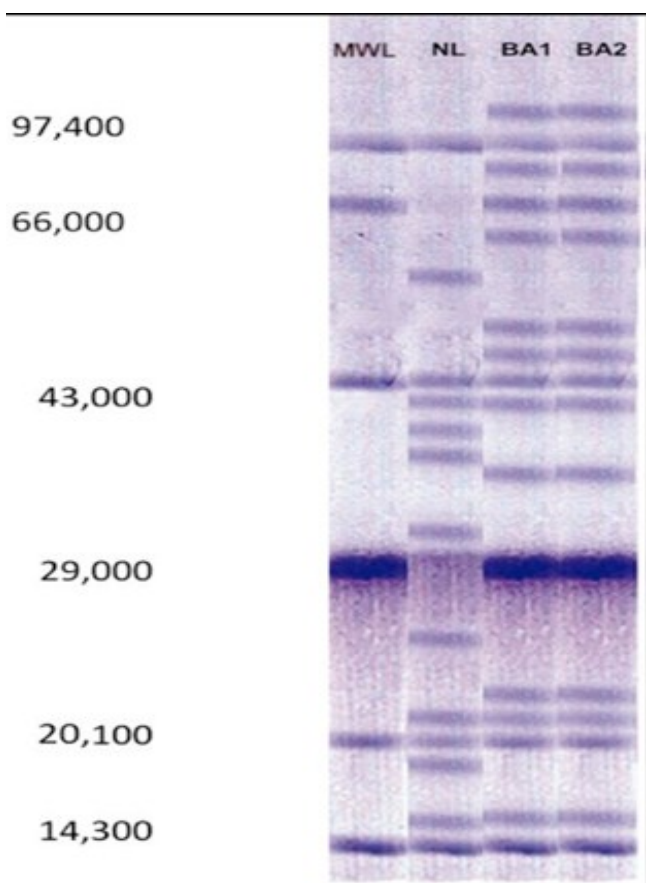

Fig. 2- Comparison of protein profiles by SDS PAGE. MWL: molecular weight ladder. NL: Normal larvae.

BA1: $0.05 \mathrm{mM}$ of benzaldehyde. BA2: $0.1 \mathrm{mM}$ of benzaldehyde.

The protein bands unique to the treated and untreated flies and those protein bands common between the treated and untreated flies are described below.

Protein Bands Common to Unexposed and Exposed Larvae One band approximately at $95,000 \mathrm{Da}$, two bands approximately at $43,000 \mathrm{Da}$, one band at $20,100 \mathrm{Da}$, one band approximately at $21,000 \mathrm{Da}$, one band at $14,300 \mathrm{Da}$ and one band approximately at $15,000 \mathrm{Da}$.

\section{Protein Bands Unique to Untreated Larvae (not Observed in Treated Larvae)}

One band approximately at 50,000 Da, 3 bands between 29,000 and $43,000 \mathrm{Da}$, one band approximately at 25,000 $\mathrm{Da}$ and one band approximately at $19,000 \mathrm{Da}$

\section{Protein Bands Unique to Treated Larvae (not Observed in Untreated Larvae)}

One band approximately at $98,000 \mathrm{Da}$, one band approximately at $95,000 \mathrm{Da}$, one band approximately at $63,000 \mathrm{Da}$, two bands approximately at $45,000 \mathrm{Da}$, one band approximately at 35,000 $\mathrm{Da}$, one band at $29,000 \mathrm{Da}$ and one band approximately at 22,000 $\mathrm{Da}$

\section{The Wing Spot Test (SMART)}

The wing spot test was performed on the trans heterozygous larvae (mwh/flr3) in all the test concentrations of benzaldehyde. The flies emerged and they were subjected to analysis by means of dissecting out the pair of wings and scoring the number of spots that indirectly helped to assess the genotoxic level of benzaldehyde (Table 2) [5]. 
Table 2- Results obtained from analysis of wing spot test on benzaldehyde exposed flies

\begin{tabular}{|c|c|c|c|}
\hline $\begin{array}{l}\text { Concentration of } \\
\text { benzaldehyde }\end{array}$ & $\begin{array}{l}\text { Pair of wings } \\
\text { Scored }\end{array}$ & $\begin{array}{l}\text { Number of spots/ } \\
\text { wing }\end{array}$ & Other changes on the wing \\
\hline Control & 10 & Absence of spots & - \\
\hline $0.05 \mathrm{mM}$ & 10 & Absence of spots & - \\
\hline $0.1 \mathrm{mM}$ & 10 & Absence of spots & - \\
\hline $0.1 \mathrm{M}$ & 10 & Absence of spots & - \\
\hline \multirow[t]{3}{*}{$0.2 \mathrm{M}$} & 2 & $4+4$ & \multirow{3}{*}{$\begin{array}{l}\text { Some areas of the wing were } \\
\text { seen with mild patches where } \\
\text { there was complete loss of } \\
\text { hair distribution. }\end{array}$} \\
\hline & 2 & $4+6+1$ (twin spot) & \\
\hline & 3 & $6+5$ & \\
\hline
\end{tabular}

\section{Discussion}

The present study evaluated the genotoxicity of benzaldehyde using the Wing Spot Assay. Adult male flies were exposed to different concentrations of benzaldehyde. The concentrations exposed were $0.05 \mathrm{mM}, 0.1 \mathrm{mM}, 0.1 \mathrm{M}, 0.2 \mathrm{M}, 0.3 \mathrm{M}$ and $0.5 \mathrm{M}$. The flies exposed to the above concentrations survived and after 48 hours the flies were allowed to breed with virgin females. Analysis of the flies under stereo microscope revealed significant changes in the phenotype in terms of orange discoloration of thorax, darkening of eye color. The exact mechanism behind the color change remains unclear and could be due to somatic mutation or toxic effects of the drug.

Third instar larvae trans-heterozygous for two genetic markers mwh and flr3, were treated at the above mentioned concentrations of benzaldehyde. Wings of the emerging adult flies were scored for the presence of spots of mutant cells, which result from either somatic mutation or mitotic recombination. The appearance of single spots clearly indicated the contribution of flr3 clone and the twin spots represented the mwh clone. In order to evaluate the exact genotoxic effect, the frequencies of spots per wing in the treated series were compared to the control group. The results of the wing spot assay are indicative of point mutation, chromosomal alteration and mitotic recombination and were quiet significant in the assessment of the genotoxic effects of benzaldehyde. [12, 13, 14]. The wing spot assay has demonstrated genetic mutations at concentrations of $0.2 \mathrm{M}, 0.3 \mathrm{M}$ and $0.5 \mathrm{M}$. However no spots were observed in $0.05 \mathrm{mM}, 0.1 \mathrm{mM}$ and $0.1 \mathrm{M}$ concentrations. The results distinctly demonstrate that concentrations of $0.2 \mathrm{M}$ and above are genotoxic as indicated by wing spot assay.

To evaluate the genotoxicity at the molecular level, proteins were isolated from exposed and unexposed third instar larvae. Significant amounts of proteins were isolated (from $0.05 \mathrm{mM}$ and $0.1 \mathrm{mM}$ ) to perform a protein profile by SDS PAGE. The profile showed the presence of eight unique bands which were not observed in the control flies. This could be a consequence of genetic mutations which has resulted in altered protein expression. However, the exact role of unique these proteins have not been elucidated and further characterization of these unique proteins may direct towards the exact mechanism of genetic alteration and function of the altered protein. Also the 50,000Da protein was absent. This could be attributed to mutations in yellow gene on $\mathrm{X}$ chromosome and producing body color changes. However the protein concentration as estimated by Bradford method for the concentrations $0.1 \mathrm{M}, 0.2 \mathrm{M}, 0.3 \mathrm{M}$ and $0.5 \mathrm{M}$ were insignificant and was not sufficient for protein profiling. This could be attributed to genotoxic effects of benzaldehyde at higher concentrations which has result- ed in loss of expression of total protein content in larvae exposed to such higher concentrations.

The present study has directed evaluation of genotoxic potential of benzaldehyde at six different molar concentrations and assessing the same at phenotypic expression, wing spot assay and protein profiling. The phenotypic of all the flies exposed to all the concentrations showed marked discoloration. However the wing spot assay demonstrated concentrations above $0.2 \mathrm{M}$ to be genotoxic. The SDS PAGE protein profiling demonstrated expression of unique proteins at the lowest concentrations $(0.05 \mathrm{mM}$ and $0.1 \mathrm{MM}$ ) of benzaldehyde and loss of proteins during isolation at higher concentrations.

However, the scope of this study is beyond evaluating the exact type of mutation, its mechanism and also defining the exact region involved in the phenotypic changes observed. Further evaluation can be directed in terms of analyzing the chromosomes for rearrangements and using PCR specific tools to study gene mutations. This could bring an insight into the specific roles of gene sequences in the expression of the phenotype and characterizing them would help us define the mutation and the effects of the mutagen [15].

\section{References}

[1] Demerec M. and Kaufman P. (1996) Drosophila Guide: Introduction to the genetics and cytology of Drosophila melanogaster, $10^{\text {th }}$ edition.

[2] Chung K.T. and Gadupudi G.S. (2011) Environmental Molecular Mutagen, 52(2), 81-104.

[3] Vamvakas S., Dekant W. and Anders M.W. (1989) Biochemical pharmacology, 38(6), 935-939.

[4] Rosario R.A., Castneda S. and Guadalupe O.T. (2004) Mutation Research, 19, 121-127.

[5] Eugenia H.P. (2004) Mutagenesis, 19(3), 187-193.

[6] Esref D., Serap K. and Bülent Kaya (2008) Food and chemical Toxicology, 46(3), 1034-1041.

[7] Lawrence S.B., Goldstein E.A. and Fyrberg (1994) Practical uses in cell and molecular biology.

[8] Squire R. (2002) Advanced Genetics.

[9] Daryl S.H. (2000) Methods in Molecular Biology: Drosophila Cytogenetic Protocols, 247.

[10]Robert E.K. (1999) Lords of the Fly.

[11]Taisei Nomura (1979) Cancer Research, 39, 4224-4227.

[12]Sarikaya R. and Yuksel M. (2008) Food and Chemical Toxicology, 46, 3159-3162.

[13]Alan J. (1987) Environmental and Molecular Mutagenesis, 10, 197-293.

[14]Marcelo T., Maria L., Gilberto S., Kenya S.C. and Heloisa R.A. (2002) Mutation Research, 519, 141-149.

[15]Anthony J.F.G., Susan R.W., Richard C.L. and Sean B.C. (2007) Introduction to Genetic Analysis. 